Supporting Information

for

\title{
Diabetes-Associated Mutations in Human Insulin: Crystal Structure and Photo-Cross-Linking Studies of A-Chain Variant Insulin Wakayama
}

Zhu-li Wan, Kun Huang, Bin Xu, Ying-Chi Chu, Shi-Quan Hu, Panayotis G. Katsoyannis, and Michael A. Weiss

\section{Table of Contents}

Purpose of Supplement. . . . . . . . . . . . . . . . . . . 2

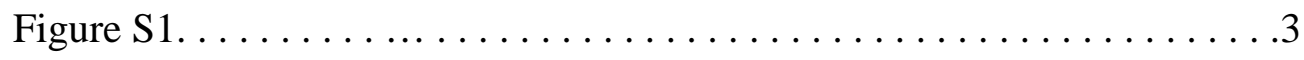

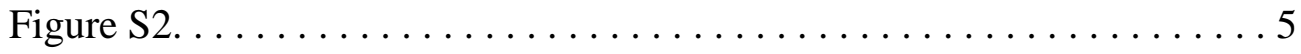

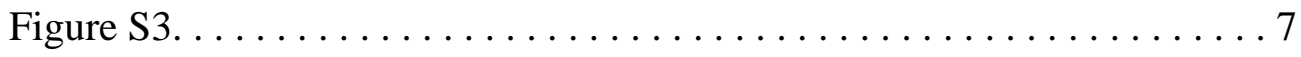

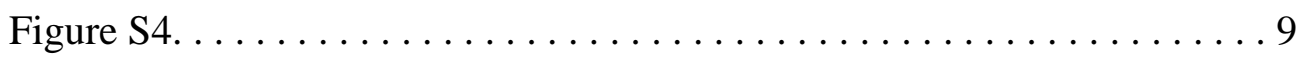

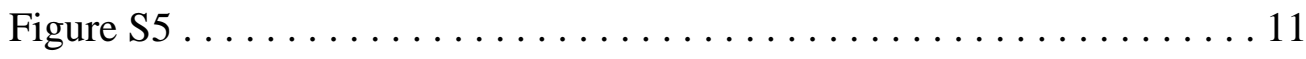

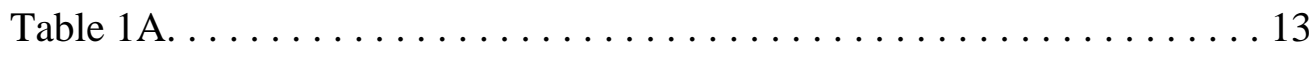

Table 1B....................................... 14

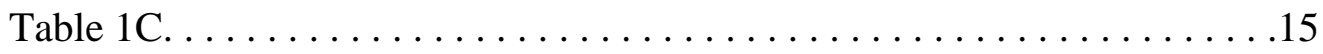

Table 2 A....................................... 16

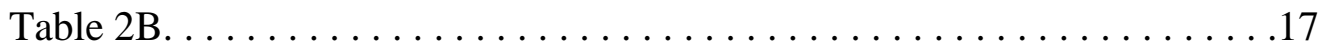




\section{Purpose of Supplement}

The purpose of the Supplement is to provide five figures and two sets of tables. Figure S1 provides an overview of the crystal structure of $\mathrm{Leu}^{\mathrm{A} 3}$-insulin as ribbon model with alignment of molecules 1 and 2. Figures S2 and S3 illustrate additional regions of the electron-density map respectively depicting bound phenol molecules and one of the zinc coordination sites. Figure S4 provides CD spectra of photo-stable Pmp insulin analogs. Figure S5 provides a Ramachandran map of $\mathrm{Leu}^{\mathrm{A} 3}$-insulin (molecules 1 and 2). The first set of supplemental tables provides quantitative comparisons between $\mathrm{Leu}^{\mathrm{A} 3}$-insulin and wild-type insulin (Tables S1-A, B, and C). The second set of supplemental tables provides distances between the A3 side chain in structures of Leu ${ }^{\mathrm{A} 3}$-insulin and wild-type insulin (Tables S2-A and S2-B, respectively). 
Figure S1. Stereoview showing superposition of crystal structure of Leu ${ }^{\mathrm{A} 3}$ insulin of molecule 1 and molecule 2. (A) Ribbon representation of crystal structure. The A-chain of molecule 1 is shown in red and the B-chain in green. Ribbon model of molecule 2 is shown in black. Disulfide bridges between residues $\mathrm{Cys}^{\mathrm{A} 6}$ and $\mathrm{Cys}^{\mathrm{A} 11}$, $\mathrm{Cys}^{\mathrm{A} 7}$ and $\mathrm{Cys}^{\mathrm{B} 7}$, and $\mathrm{Cys}^{\mathrm{A} 20}$ and $\mathrm{Cys}^{\mathrm{B} 19}$ are shown in yellow. (B) Stereo packing schemes of $\mathrm{Leu}^{\mathrm{A} 3}$-insulin (red) in the hydrophobic core of molecule 1. Residues $\mathrm{Il}^{\mathrm{A} 2}, \mathrm{Leu}^{\mathrm{A} 16}$, and $\mathrm{Tyr}^{\mathrm{A} 19}$ are shown in gray; residues $\mathrm{Leu}^{\mathrm{B} 11}$, $\mathrm{Leu}^{\mathrm{B} 15}$, $\mathrm{Phe}^{\mathrm{B} 24}$ and $\mathrm{Tyr}^{\mathrm{B} 26}$ in green and residues $\mathrm{Cys}^{\mathrm{A} 7}$ and $\mathrm{Cys}^{\mathrm{B} 7}$ in yellow. Molecule 2 is shown in black. 

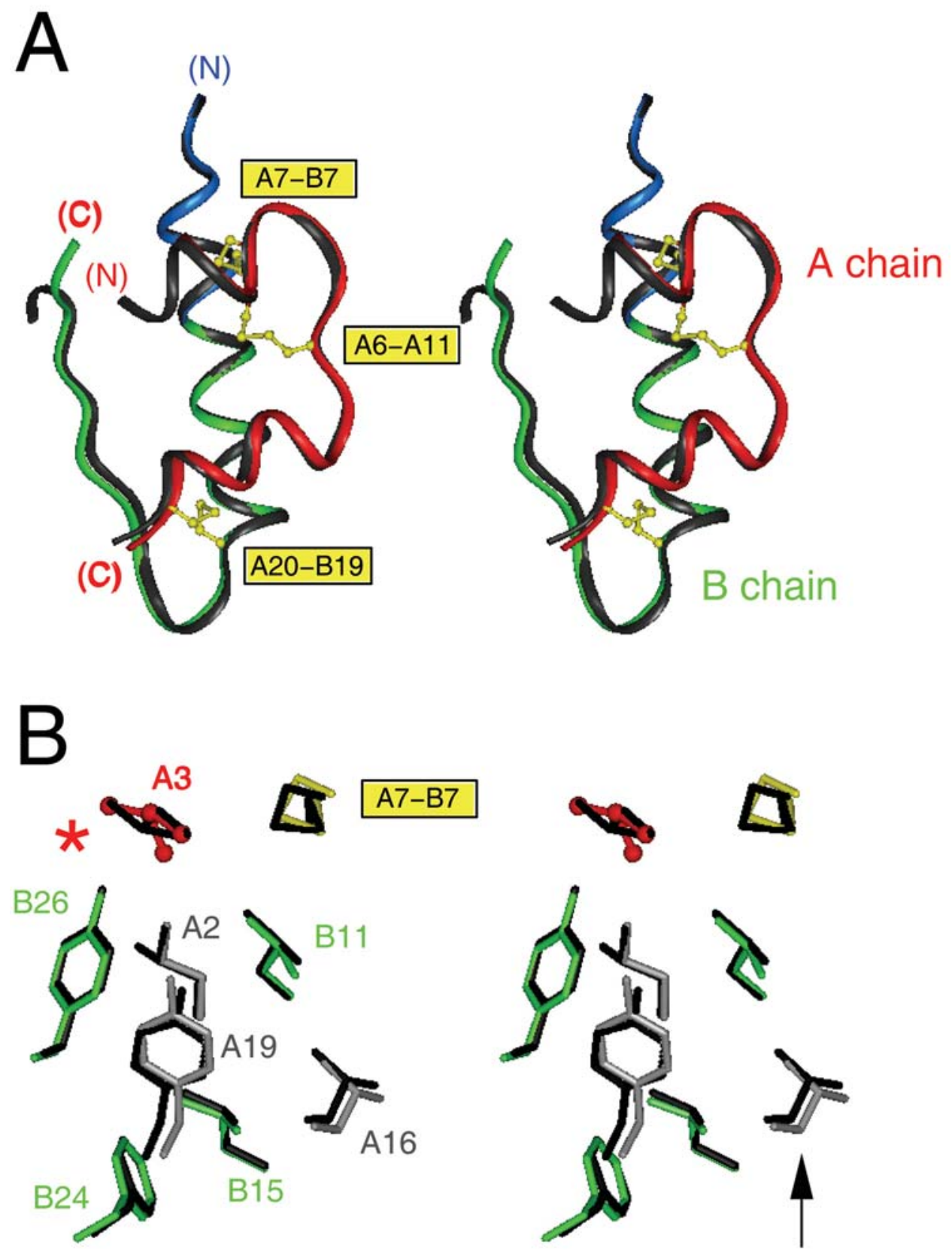

Fig. S1 
Figure S2. 2Fo-Fc electron density map contoured at a level of $1.0 \sigma$. (A) Atomic positions of residues A1-A4 of $\mathrm{Leu}^{\mathrm{A} 3}$-insulin (molecule 1). (B) Atomic positions of residues A1-A4 of Leu ${ }^{\mathrm{A} 3}$ insulin (molecule 2). (C) Phenol molecule in Leu ${ }^{\mathrm{A} 3}$-insulin of molecule 1. The phenol molecule is capable of forming hydrogen bonds to the carbonyl $\mathrm{O}$ atom of $\mathrm{Leu}^{\mathrm{A} 6}$ (dashed line; a contact of $2.87 \AA$ ) and the $\mathrm{N}$ atom of $\mathrm{Cys}^{\mathrm{A} 11}$ (dashed line, a contact of $2.87 \AA$ ). (D) Phenol molecule in the cubic structure of molecule 2. It is capable of forming hydrogen bonds to the carbonyl $\mathrm{O}$ atom of Leu $^{\mathrm{A} 6}$ (dashed line; contact of $2.81 \AA$ ) and the $\mathrm{N}$ atom of $\mathrm{Cys}^{\mathrm{A} 11}$ (dashed line; contact of $3.12 \AA$ ). 

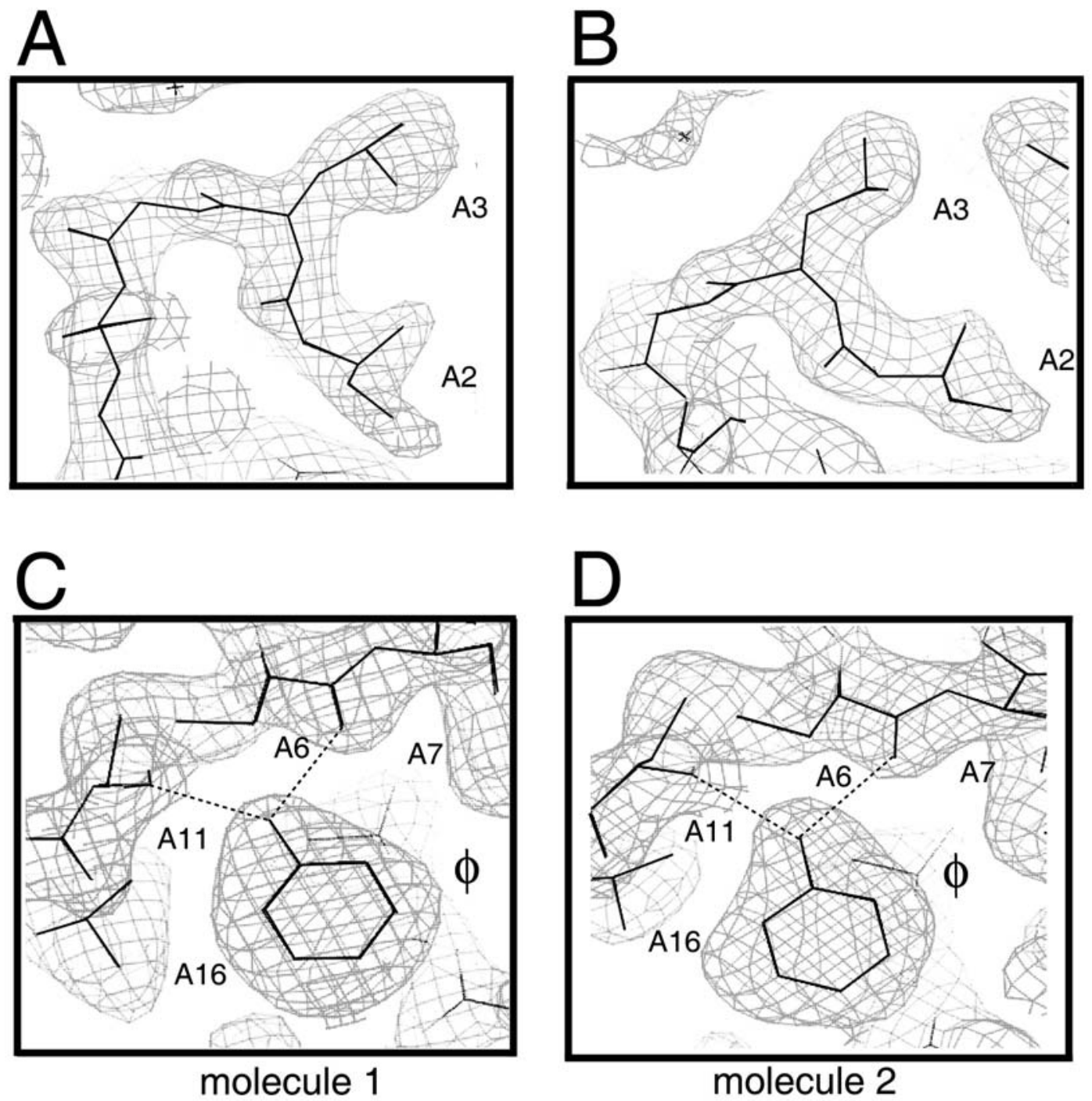

Fig. S2 
Figure S3. $2 F o-F c$ electron density map contoured at a level of $1.0 \sigma$. (A) Zinc ion in the $\mathrm{R}_{3}$ trimer of the $\mathrm{Leu}^{\mathrm{A} 3}$-insulin hexamer of molecule 1, shown parallel to the crystallographic 3-fold axis. Coordination geometry is tetrahedral. (B) $\mathrm{R}_{3}$ trimer of the $\mathrm{Leu}^{\mathrm{A} 3}$-insulin hexamer of molecule 2. 


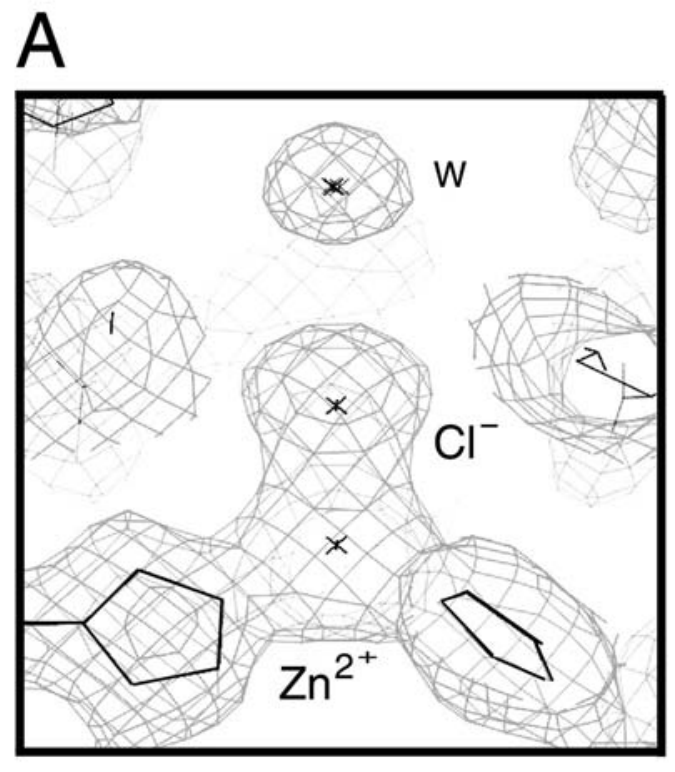

molecule 1

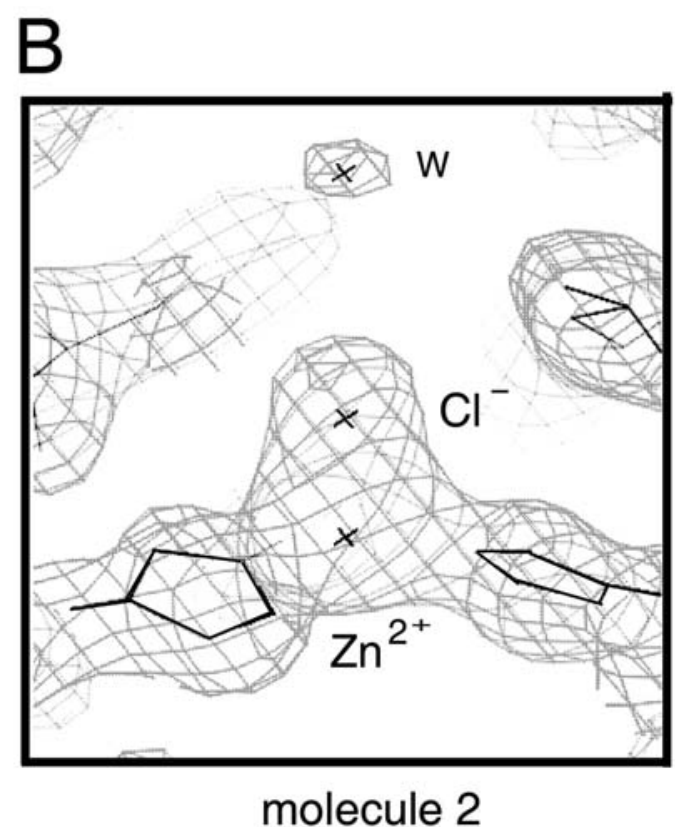

Fig. S3 
Figure S4. CD studies of Pmp derivatives of insulin. Far-UV CD spectra of analogues containing para-amino-phenylalanine (Pmp) at A3 and A14 (triangles and open circles, respectively) relative to spectrum of human insulin (filled circles). $\mathrm{Pmp}^{\mathrm{A} 3}$ - and $\mathrm{Pmp}^{\mathrm{A} 14}$ derivatives also contain a biotin tag at $\mathrm{A} 1$ as described in text. Spectra were observed at $\mathrm{pH} 7.4$ and $4{ }^{\circ} \mathrm{C}$. The spectrum of the $\mathrm{Pmp}^{\mathrm{A} 3}$ analogue suggests a perturbation in secondary structure or dynamics; however, a contribution of an ordered Pmp ring in this spectral region cannot be excluded. 


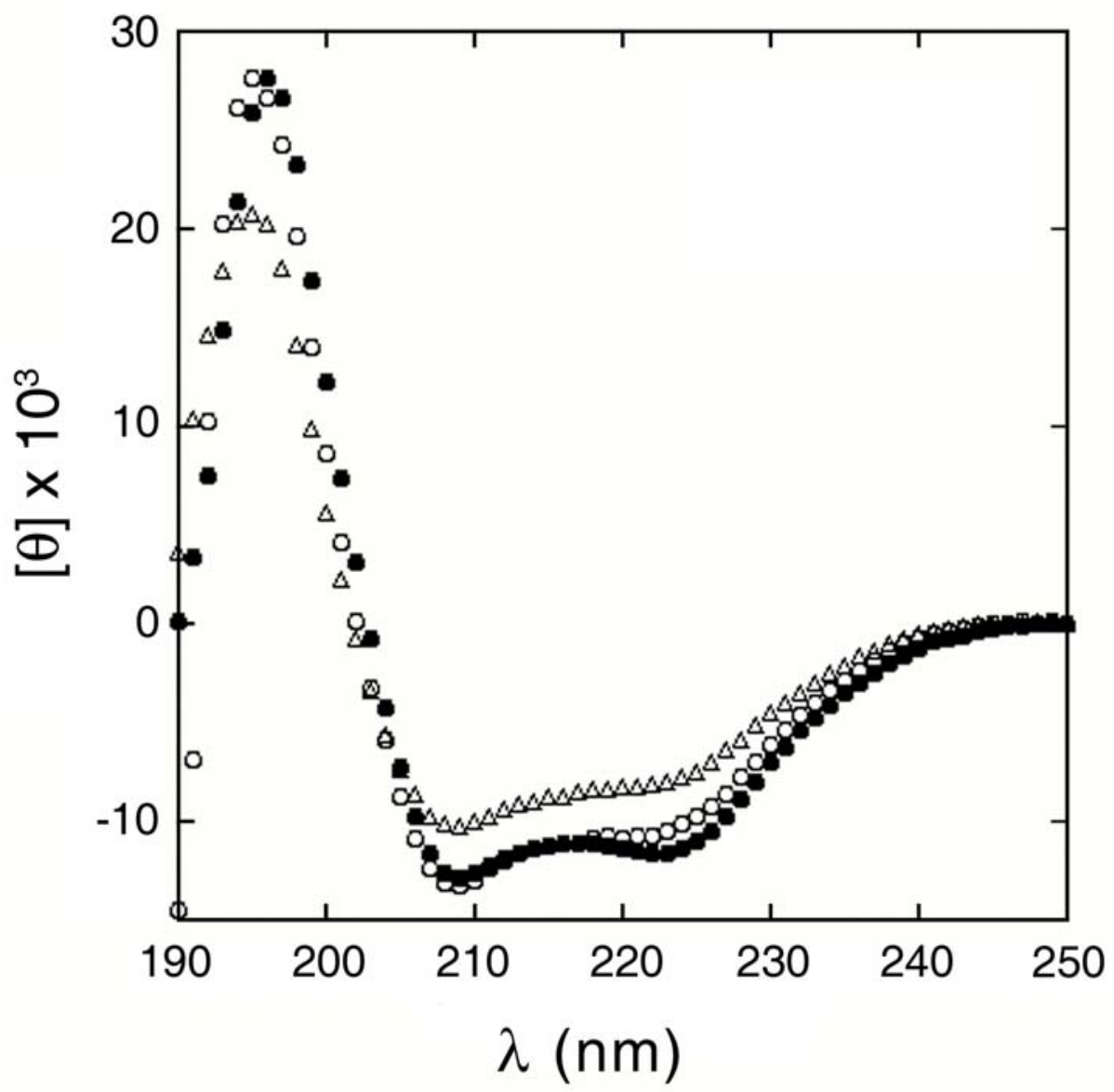

Fig. S4 
Figure S5. Ramachandran map of Leu ${ }^{\mathrm{A} 3}$-insulin (molecules 1 and 2). Map resembles that of Rstate protomers of wild-type insulin (PDB entries 1BEN, 1EV3, 1EV6, 1G7A, 1G7B, 1MPJ, 1TRZ, 1TYL, 1TYM, 1ZNJ, and 3MTH). 


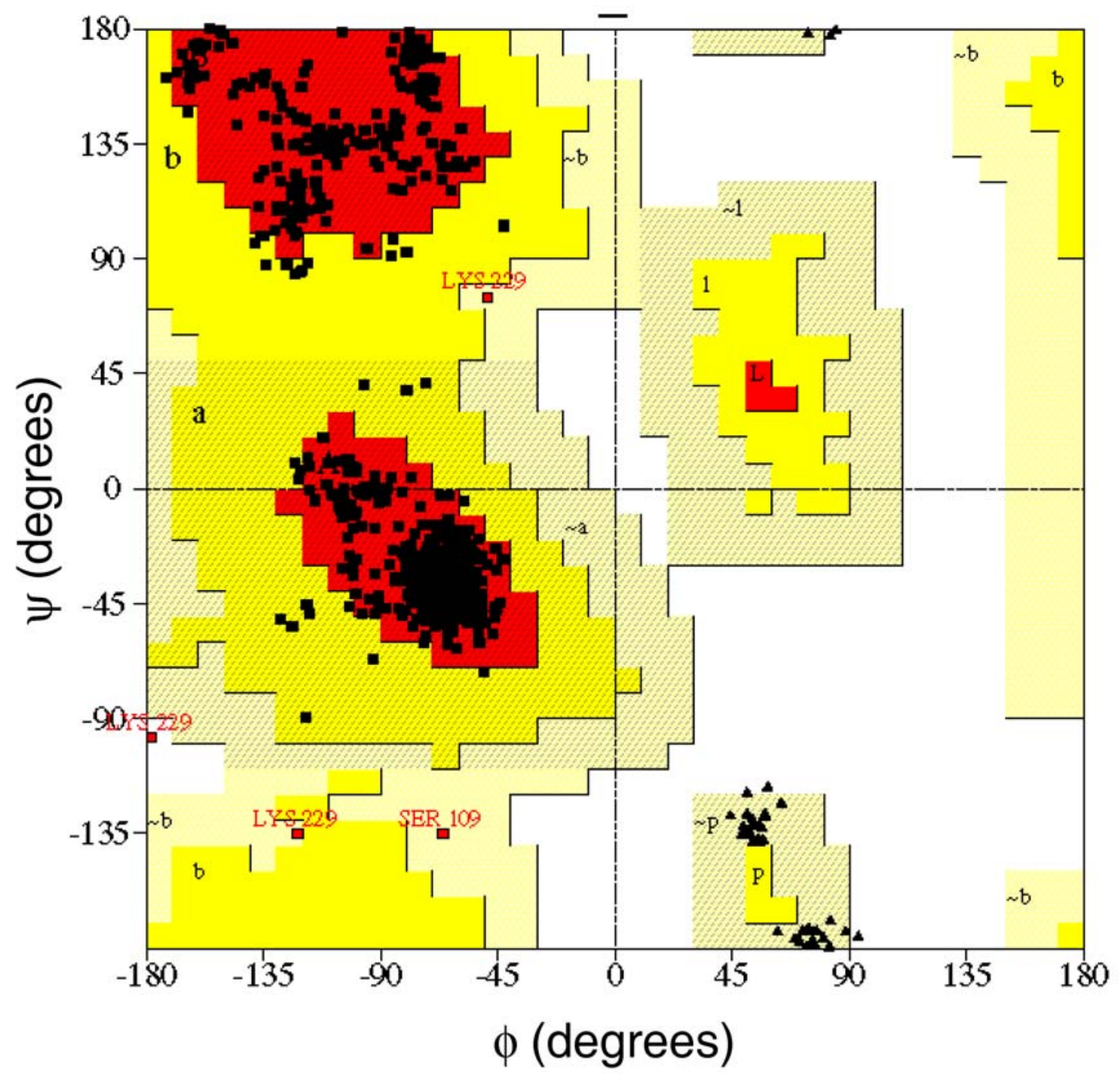

Fig. S5 
Table S1-A. RMSD of Leu ${ }^{\mathrm{A} 3}$-insulin (molecule 1) relative to wild-type R-state protomers ${ }^{\mathrm{a}, \mathrm{b}}$

\begin{tabular}{|c|c|c|c|}
\hline struc & ctures & $\begin{array}{l}n \text {-chain } \\
(\AA)\end{array}$ & $\begin{array}{l}\text { side-chain } \\
(\AA)\end{array}$ \\
\hline $1 \mathrm{BEN}$ & $R \quad$ (4ZN T3R3) & 0.78 & 1.31 \\
\hline 1TRZ & $R \quad(4 \mathrm{ZN}$ T3R3) & 0.92 & 1.36 \\
\hline 1TYL & $R(4 \mathrm{ZN}$ T3R3) & 0.49 & 1.04 \\
\hline 1TYM & $R \quad(4 \mathrm{ZN}$ T3R3) & 0.57 & 1.11 \\
\hline $1 \mathrm{ZNI}$ & $\mathrm{R}(4 \mathrm{ZN}$ T3R3) & 0.78 & 1.58 \\
\hline $1 \mathrm{MPJ}$ & $R(4 \mathrm{ZN}$ T3R3) & 0.63 & 1.49 \\
\hline ЗМTH & R (4ZN T3R3) & 0.78 & 1.68 \\
\hline $6 \mathrm{INS}$ & $\mathrm{R}$ (mini-proinsulin) & 0.65 & 1.46 \\
\hline $1 \mathrm{G} 7 \mathrm{~A}$ & R1 (rhom T3R3) & 0.79 & 1.40 \\
\hline & $\mathrm{R} 2$ & 0.65 & 1.22 \\
\hline $1 \mathrm{LPH}$ & R (KP T3R3) & 0.93 & 1.61 \\
\hline $1 \mathrm{EV} 3$ & R1 (rhom R2) & 0.58 & 1.29 \\
\hline & R2 & 0.57 & 0.10 \\
\hline IZEG & R1 (rhom R2) & 0.63 & 1.15 \\
\hline & R2 & 0.54 & 1.34 \\
\hline $1 \mathrm{ZEH}$ & R1 (rhom R2) & 0.78 & 1.40 \\
\hline & R2 & 0.63 & 1.58 \\
\hline $1 \mathrm{ZNJ}$ & R1 (monoclinic) & 0.55 & 1.20 \\
\hline & R2 & 0.50 & 1.27 \\
\hline & R3 & 0.38 & 1.03 \\
\hline & R4 & 0.50 & 1.06 \\
\hline & R5 & 0.49 & 1.02 \\
\hline & R6 & 0.54 & 0.95 \\
\hline $1 \mathrm{EV} 6$ & R1 (monoclinic) & 0.52 & 1.15 \\
\hline & R2 & 0.56 & 1.12 \\
\hline & R3 & 0.58 & 1.37 \\
\hline & R4 & 0.63 & 1.16 \\
\hline & R5 & 0.52 & 1.14 \\
\hline & R6 & 0.55 & 1.04 \\
\hline avera & age & $0.62( \pm 0$ & $1.26( \pm 0.20)$ \\
\hline
\end{tabular}

${ }^{a}$ Structures were aligned pairwise according to the main-chain atoms of residues B3-B28 and A2-A20. The baseline RMSDs between molecules 1 and 2 in the crystal structure of Leu $^{\mathrm{A} 3}$-insulin are $0.47 \AA$ (main chain) and $1.25 \AA$ (side chain). ${ }^{\mathrm{b}} \mathrm{T}_{3} \mathrm{R}_{3}{ }^{\mathrm{f}}$ structures contain $\mathrm{R}^{\mathrm{f}}$ promoters, which differ from canonical $\mathrm{R}$ state in $\mathrm{R}_{6}$ zinc-phenol hexamers due to fraying of terminal residues B1 and B2 in B-chain $\alpha$-helix. 
Table S1-B. RMSD of Leu ${ }^{\mathrm{A} 3}$-insulin (molecule 2) relative to wild-type R-state protomers ${ }^{\mathrm{a}, \mathrm{b}}$

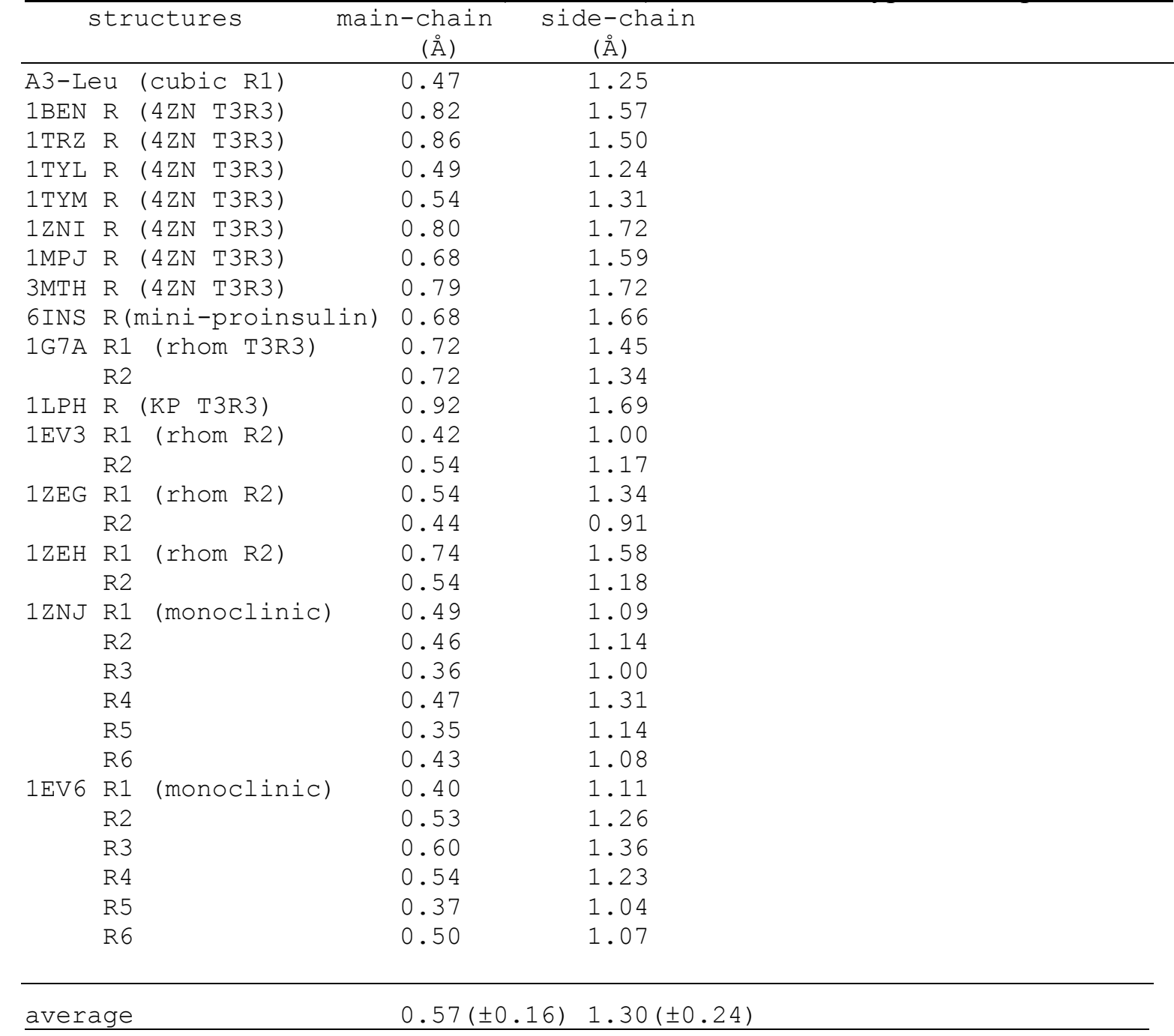

${ }^{\mathrm{a}}$ Structures were aligned pairwise according to the main-chain atoms of residues B3-B28 and A2-A20. The baseline RMSDs between molecules 1 and 2 in the crystal structure of $\mathrm{Leu}^{\mathrm{A} 3}$-insulin are $0.47 \AA$ (main chain) and $1.25 \AA$ ( side chain). ${ }^{\mathrm{b}} \mathrm{T}_{3} \mathrm{R}_{3}$ structures contain $\mathrm{R}^{\mathrm{f}}$ promoters, which differ from canonical $\mathrm{R}$ state in $\mathrm{R}_{6}$ zinc-phenol hexamers due to fraying of terminal residues B1 and B2 in B-chain $\alpha$-helix 
Table S1-C. Baseline variability among wild-type crystal structures: RMSD between a prototypical wild-type insulin R state (1TRZ) and other wild-type crystal structures ${ }^{\mathrm{a}}$

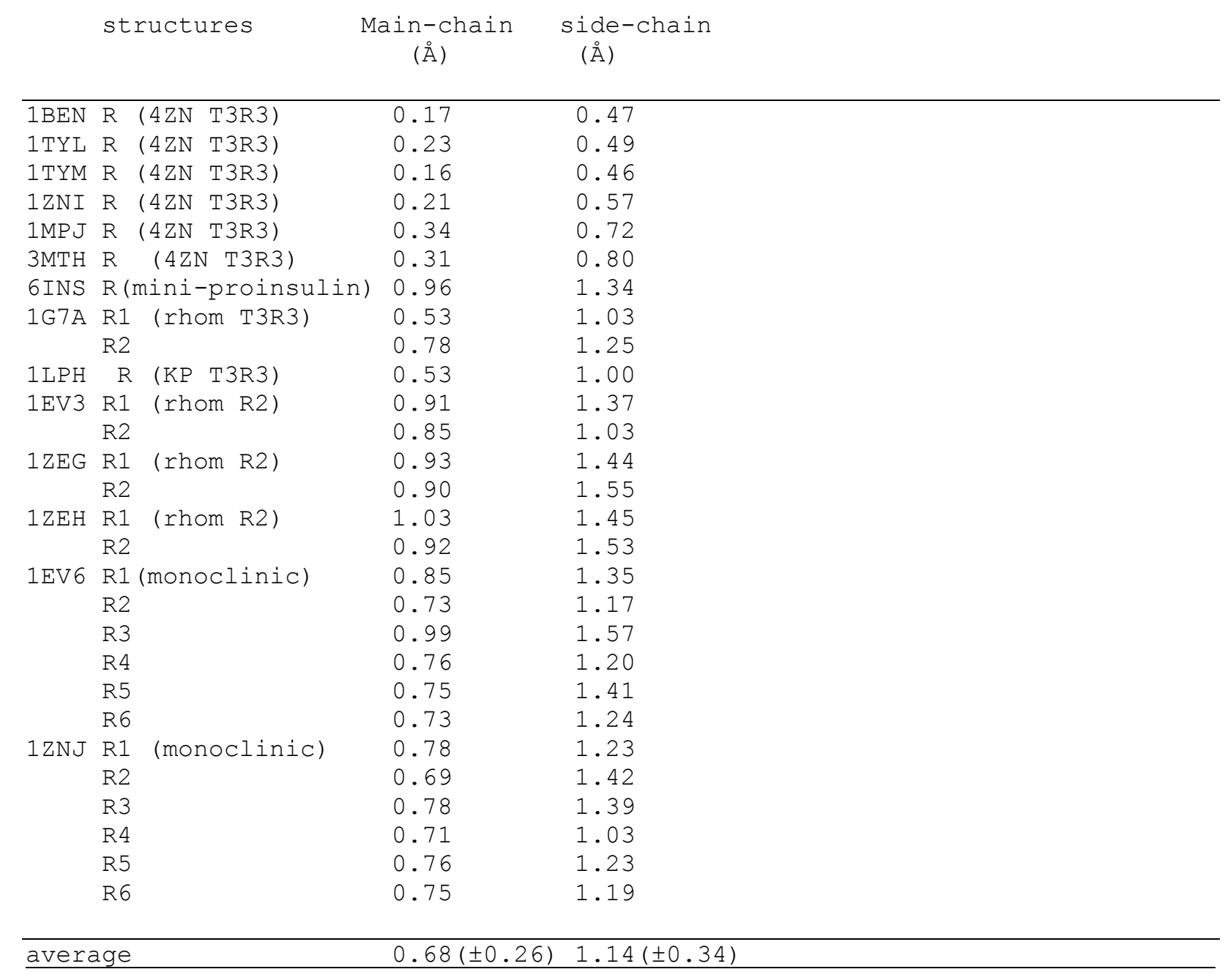

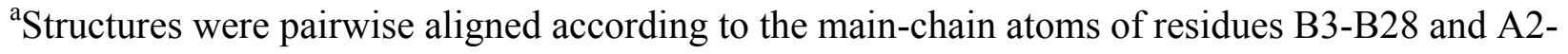
A20. 
Table S2-A: Contacts of A3 side chain in Leu ${ }^{\mathrm{A} 3}$-insulin ${ }^{\mathrm{a}}$

\begin{tabular}{llllcc} 
& & molecule 1 & molecule 2 \\
\hline A3 -LEU -CD1 --- & A2 & -ILE-CG1 & 5.7 & 7.5 \\
A3 -LEU -CD1 --- & A2 & -ILE-CG2 & 4.3 & 5.5 \\
A3 -LEU -CD1 --- & A2 & -ILE-CD1 & 6.5 & 8.3 \\
A3 -LEU -CD2 --- & A2 & -ILE-CG2 & 5.7 & 4.9 \\
A3 -LEU -CD1 --- & A4 & -GLU-OE1 & 6.5 & 5.7 \\
A3 -LEU -CD1 --- & A4 & -GLU-OE2 & 6.6 & 5.0 \\
A3 -LEU -CD2 --- & A4 & -GLU-OE1 & 5.8 & 6.9 \\
A3 -LEU -CD2 --- & A4 & -GLU-OE2 & 5.3 & 6.4 \\
A3 -LEU -CD1 --- & A6 & -CYS-CB & 6.9 & 9.0 \\
A3 -LEU -CD1 --- & A7 & -CYS-SG & 4.2 & 5.7 \\
A3 -LEU -CD2 --- & A7 & -CYS-SG & 5.9 & 3.6 \\
A3 -LEU -CD2 ---- B4 & -GLN -NE2 & 3.8 & 5.4 \\
A3 -LEU -CD2 ---- B4 & -GLN -OE1 & 4.7 & 6.3 \\
A3 -LEU -CD1 --- & B4 & -GLN -NE2 & 5.4 & 3.9 \\
A3 -LEU -CD1 --- & B4 & -GLN -OE1 & 5.8 & 5.1 \\
A3 -LEU -CD1 ---- B7 & -CYS -SG & 5.6 & 7.5 \\
A3 -LEU -CD2 ---- B7 & -CYS -SG & 7.5 & 5.2 \\
A3 -LEU -CD1 --- & B11 & -LEU -CD1 & 3.9 & 6.1 \\
A3 -LEU -CD2 --- & B11 & -LEU -CD1 & 6.4 & 3.8 \\
A3 -LEU -CD1 ---- B26 & -TYR -OH & 3.4 & 3.9 \\
A3 -LEU -CD2 ---- B26 & -TYR -OH & 3.8 & 3.7 \\
A3 -LEU -CD1 ---- B28 & -PRO -CB & 4.9 & 3.6 \\
A3 -LEU -CD1 ---- B28 & -PRO -CG & 6.2 & 4.9 \\
A3 -LEU -CD2 ---- B28 & -PRO -CB & 3.6 & 5.1 \\
A3 -LEU -CD2 ---- B28 & -PRO -CG & 4.9 & 6.3 \\
\hline
\end{tabular}

${ }^{\mathrm{a}}$ The $\mathrm{Leu}^{\mathrm{A} 3}$ side chains in molecules 1 and 2 each project from the $\mathrm{N}$ terminal A-chain $\alpha$-helix to contact the C-terminal $\beta$-strand within a corresponding crevice lined. 
Table S2-B: Contacts of residue A3 side chain in native insulin ${ }^{\mathrm{a}}$

\begin{tabular}{|c|c|c|c|c|c|c|c|c|c|}
\hline \multirow[b]{3}{*}{ A3 } & \multirow[b]{3}{*}{$-\mathrm{VAL}$} & \multirow[b]{3}{*}{$-\mathrm{CG} 1$} & \multirow[b]{3}{*}{---} & \multirow[b]{3}{*}{ A2 } & \multirow[b]{3}{*}{-ILE-CG2 } & \multicolumn{2}{|c|}{$\mathrm{T}$ state } & \multirow{2}{*}{\multicolumn{2}{|c|}{$\begin{array}{c}\text { R state } \\
\text { molecule } 1 \text { molecule } 2\end{array}$}} \\
\hline & & & & & & molecule 1 & molecule 2 & & \\
\hline & & & & & & & & 4.0 & 5.9 \\
\hline A3 & -VAL & $-\mathrm{CG} 2$ & --- & A2 & -ILE-CGI & 6.2 & 5.8 & 6.9 & 5.6 \\
\hline A3 & -VAL & $-\mathrm{CG} 2$ & --- & A2 & -ILE-CG2 & 4.1 & 4.0 & 5.7 & 3.6 \\
\hline A3 & -VAL & $-\mathrm{CG} 1$ & --- & A 4 & -GLU-OE 1 & 4.2 & 4.8 & 5.1 & 5.2 \\
\hline A3 & -VAL & $-\mathrm{CG} 1$ & --- & A4 & -GLU-OE2 & 5.3 & 3.8 & 5.3 & 7.2 \\
\hline A3 & -VAL & $-\mathrm{CG} 2$ & --- & A4 & -GLU-OE 1 & 5.0 & 5.0 & 3.7 & 5.2 \\
\hline A3 & -VAL & $-\mathrm{CG} 2$ & --- & A 4 & -GLU-OE2 & 5.4 & 4.8 & 3.4 & 6.0 \\
\hline A3 & -VAL & $-\mathrm{CG} 1$ & --- & A 6 & $-\mathrm{CYS}-\mathrm{CB}$ & 7.4 & 6.8 & 7.2 & 7.5 \\
\hline A3 & -VAL & $-\mathrm{GG} 1$ & --- & A 6 & $-C Y S-S G$ & 8.6 & 7.4 & 8.3 & 8.7 \\
\hline A3 & -VAL & $-\mathrm{CG} 1$ & --- & A7 & $-\mathrm{CYS}-\mathrm{CB}$ & 4.1 & 6.2 & 6.1 & 4.6 \\
\hline A3 & -VAL & $-\mathrm{CG} 1$ & --- & A7 & $-\mathrm{CYS}-\mathrm{SG}$ & 4.6 & 7.2 & 5.1 & 4.2 \\
\hline A3 & -VAL & $-\mathrm{CG} 1$ & --- & B11 & - LEU -CD1 & 7.8 & 6.7 & 4.5 & 5.9 \\
\hline A3 & -VAL & $-\mathrm{CG} 1$ & --- & B11 & - LEU -CD2 & 5.7 & 4.2 & 6.8 & 8.2 \\
\hline A3 & -VAL & $-\mathrm{CG} 2$ & --- & B11 & $-\mathrm{LEU} \quad-\mathrm{CD} 1$ & 6.9 & 6.0 & 6.3 & 4.6 \\
\hline A3 & -VAL & $-\mathrm{CG} 2$ & --- & B11 & - LEU -CD2 & 4.6 & 4.1 & 8.3 & 6.9 \\
\hline A3 & -VAL & $-\mathrm{CG} 1$ & ---- & B26 & $-\mathrm{TYR}-\mathrm{OH}$ & 5.9 & 3.7 & 3.4 & 5.6 \\
\hline A3 & -VAL & $-\mathrm{CG} 2$ & ---- & B2 6 & $-\mathrm{TYR}-\mathrm{OH}$ & 4.2 & 3.7 & 5.8 & 3.6 \\
\hline A3 & -VAL & $-\mathrm{CG} 1$ & --- & B28 & $-\mathrm{PRO}-\mathrm{CB}$ & 5.9 & 3.9 & 4.3 & 6.2 \\
\hline A3 & -VAL & $-\mathrm{CG} 1$ & --- & B28 & $-\mathrm{PRO} \quad-\mathrm{CG}$ & 7.1 & 5.0 & 5.6 & 7.6 \\
\hline A3 & -VAL & $-\mathrm{CG} 2$ & --- & B28 & $-\mathrm{PRO}-\mathrm{CB}$ & 4.0 & 4.2 & 5.7 & 4.8 \\
\hline A3 & -VAL & $-\mathrm{CG} 2$ & --- & B28 & $-\mathrm{PRO}-\mathrm{CG}$ & 5.0 & 4.9 & 7.2 & 6.1 \\
\hline
\end{tabular}

${ }^{\mathrm{a}}$ The $\mathrm{Val}^{\mathrm{A} 3}$ side chains in $\mathrm{T}$-state protomers in each case project from the $\mathrm{N}$-terminal Achain $\alpha$-helix to contact the C-terminal $\beta$-strand within a corresponding crevice lined. PDB entries 4INS in T state, and 1ZNJ in R-state. 